\title{
Expansion of the Socket and Orbit for Congenital Clinical Anophthalmia
}

\author{
Karsten Kurt Helmuth Gundlach, M.D., D.D.S., M.S.D., Rudolf Friedrich Guthoff, M.D., \\ Volker Hermann Martin Hingst, D.D.S., Michael Peter Schittkowski, M.D., and \\ Ulrich Christian Bier, M.D., D.D.S.
}

Rostock, Germany

Background: Congenital clinical anophthalmia requires fitting an artificial eye, achieving a pleasing aspect of the palpebral apparatus, and stimulating growth of the orbit, as well as of the entire midface.

Methods: Out of 25 patients with clinical anophthalmia, 22 were treated according to a new protocol (first described by Wiese et al. in 1999) and followed for up to 6 years. In 10 patients, anophthalmia was bilateral, in nine patients, it was on the right side only and in three it was on the left side only. Treatment consisted of implantation of an osmotic expander to first stimulate growth of the conjunctival sac and eyelids followed by serial implantation of osmotic expanders to stimulate growth of the orbit (and thus of the midface). The material used was a copolymer of methylmethacrylate and Nvinylpyrrolidone.

Results: Fitting of an artificial eye was without any problem within the first year of life for the most part. Growth of the orbit was stimulated by more than 65 percent of a healthy one. Aesthetically, the results were very largely pleasing. Complications were encountered, especially when the wrong expander sizes had been implanted.

Conclusion: Using osmotic expanders of this type, through a staged therapy of minor operations, promises to achieve all goals before the child enters school. (Plast. Reconstr. Surg. 116: 1214, 2005.)

Next to cyclopia, anophthalmia is the most severe malformation of the eye. It not only influences the growth of the craniofacial skeleton, but also has major consequences for the overall aesthetics of the face. This anomaly is a developmental-field defect ${ }^{1}$ located in Pfeifer's diacephalic region. ${ }^{2}$ This region is defined as the (bilateral) border zone between the frontonasal and the posterolateral regions of the face and stretches from the temple, crossing the orbit and the lateral parts of the nose, including the ala nasi, running along the philtral column of the upper lip, and ending between the premaxilla and the posterolateral part of the palate and the upper jaw at the nasopalatine duct (Fig. 1). In this diacephalic region, the most common, and some of the most severe, types of craniofacial malformations are found, including isolated clefts of the lip (alveolus and palate) or of the nose, most of the Tessier-type clefts (numbers 2, 3, 4, 8, 9, 10, 11 , and 12), as well as cryptophthalmia, microphthalmia, and anophthalmia. As all of these are morphogenetically related to each other somehow, it is not surprising that anomalies of this region may be encountered in combination with each other (Fig. 2). Distur- 


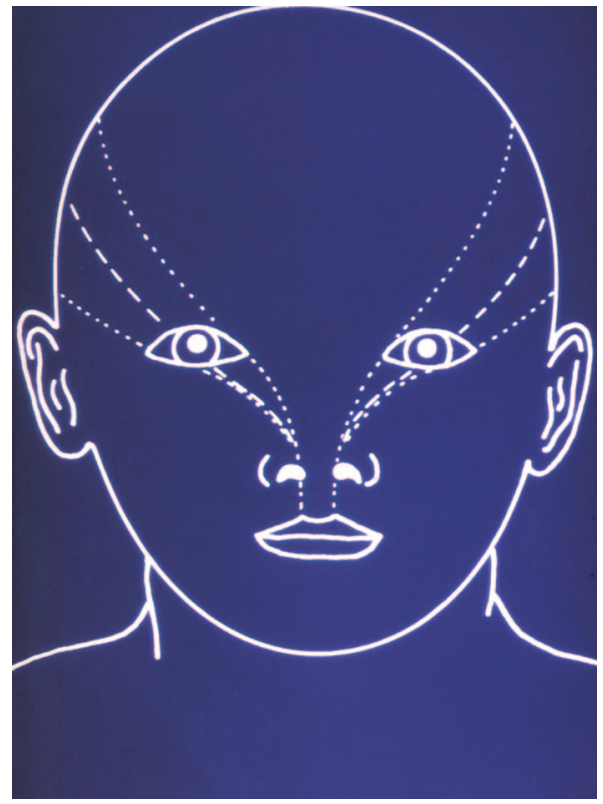

FIG. 1. Teratological regions of the head (Gundlach, K. K. H., and Pfeifer, G. Classification of facial malformations. Int. J. Oral Surg. 10: 267, 1981.)

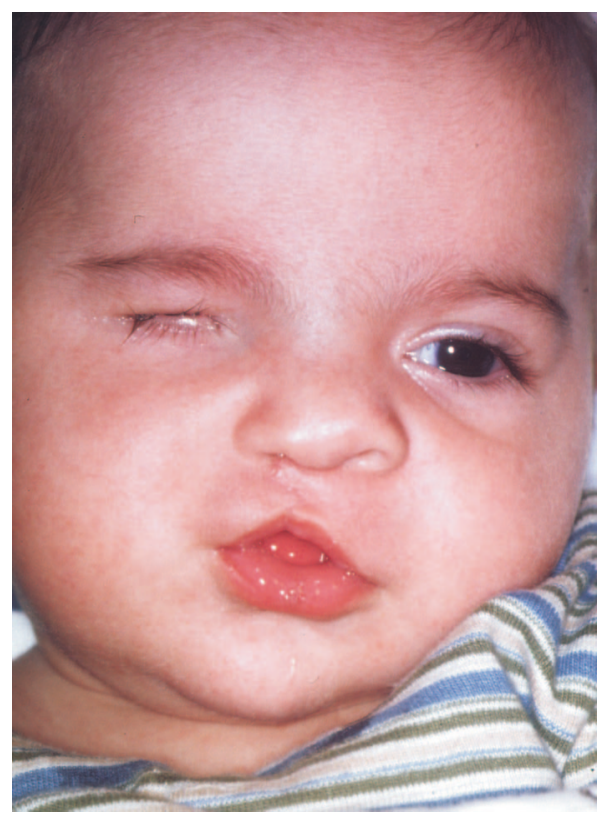

FIG. 2. Anophthalmia in combination with ipsilateral facial clefting.

bances in development of either the frontonasal region ${ }^{3}$ or the posterolateral region also may result in maldevelopment of the border of these areas, i.e., abnormalities in the diacephalic region. ${ }^{4}$ Thus, microphthalmia and (clinical) anophthalmia also may be found in conjunction with hypertelorism (a malformation of the frontonasal region; Fig. 3) or with hemifacial microsomia (a disorder of the posterolateral region; Fig. 4).

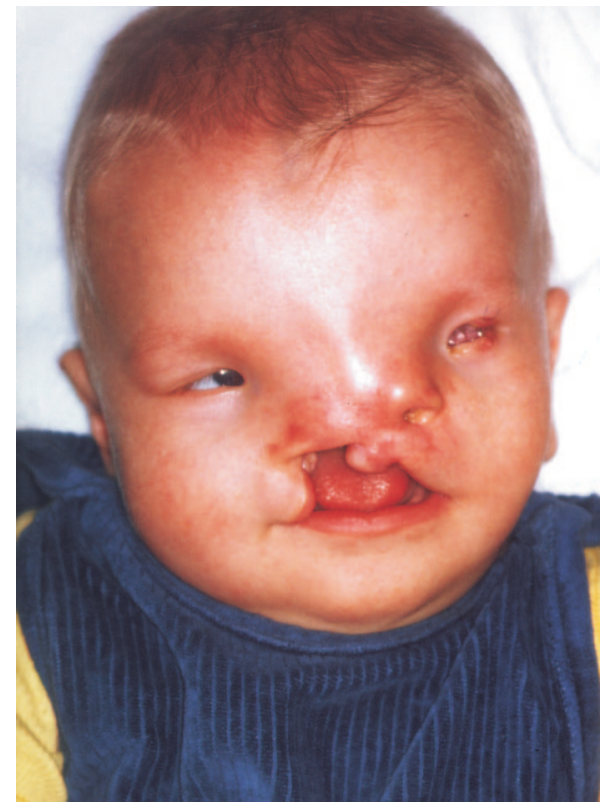

FIG. 3. Anophthalmia in combination with hypertelorism in median cleft syndrome.

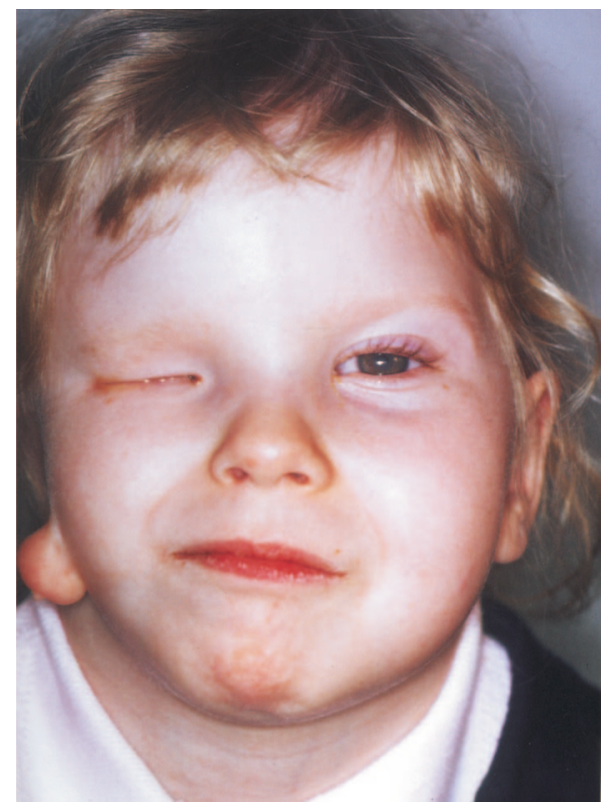

FIG. 4. Anophthalmia in combination with hemifacial microsomia.

Unilateral clinical anophthalmia (absence or extreme hypoplasia of the eyeball) always results in hypoplasia of the ipsilateral bony orbit, as there is no stimulus inducing growth of the orbital socket. ${ }^{5,6}$ This, in turn, leads to facial asymmetry with hypoplasia of the ipsilateral midface, a canted occlusal plane, and, ipsilaterally, a short ascending ramus of the mandible as a result thereof. This sequence of asymmetry becomes more and more overt during childhood and adolescence. In contrast, bilat- 
eral anophthalmia may lead to symmetrical microsomia of the midface as a whole.

The local, ophthalmological sequels of anophthalmia are minor when compared with the consequences of the poor facial development just described. For the individual patient and his/her parents, however, the missing eye, the short palpebral fissure, the sunken palpebral apparatus, and the inability to place an artificial eye are troublesome local consequences, in addition to the most disturbing shortcomings of monocular vision or bilateral blindness.

Formerly, microphthalmia and anophthalmia were treated by osteotomy of the bony orbit $^{7}$ followed by lengthening of the lashbearing $\operatorname{lid}^{8}$ and grafting of mucosa to the socket. Later, silicone expanders were recommended, but Wolfe's comment that "even in the best of circumstances, the results are poor" ${ }^{\prime 9}$ still seems to be valid. ${ }^{10}$ Even the team of the Cranio-Orbito-Palpebral Unit at Hopital Foch today prefers serial implants placed into the growing orbit when the child is young enough to justify the efforts aimed at enhancing the growth of the bony orbit. To this end, they apply implants made of either silicone or of methylmethacrylate. ${ }^{10}$

Based on the experience of Wiese et al., ${ }^{11} \mathrm{a}$ treatment protocol for clinical congenital anophthalmia applying a series of a new type of osmotic hydrogel expanders of various sizes was developed at Rostock University Hospital. ${ }^{12}$ The expander material is made of a copolymer of methylmethacrylate and N-vinylpyrrolidone. This article reports the experience with this protocol in 22 out of 25 patients between 1997 and 2003. Special reference will be made to growth and development of the length of the palpebral fissure and the anophthalmic bony orbit in this article.

\section{PATIENTS AND METHODS}

Our study included 22 (12 males, 10 females) out of 25 patients on whom the new osmotic expanders were used. In a twenty-sixth patient, a different treatment protocol was applied. Ten out of the 22 cases had bilateral congenital clinical anophthalmia while nine had unilateral anophthalmia on the right side only and three on the left side only. In addition, there was one right-sided microphthalmia treated accordingly. The following concomitant diagnoses were made with those 22 patients who had not been treated before and in whom it was possible to start our protocol (Table I). The age of these 22 patients at the time of the first surgical intervention in the Rostock University Hospitals ranged between 1 and 33 months, with the majority between 3 to 7 months (median 4 months).

\section{The Rostock Treatment Protocol Applied}

1. At approximately 3 months of age, expansion of the conjunctival sac was started by implantation of an osmotic expander of hemispheric shape with a final volume of $0.9 \mathrm{ml}$ and a final diameter of $14 \mathrm{~mm}$ (radius $7 \mathrm{~mm}$ ).

2. Approximately 2 months later, this was exchanged for either a conformer made of a glass ball (10 $\mathrm{mm}$ in diameter) or an artificial eye (in the form of a glass shell) for another 3 months to produce a smooth, nonirritated mucosal layer of the enlarged conjunctival sac.

3. At approximately 9 months of age, (approximately 5 to 6 months after the first surgical intervention), the bony orbit was further expanded starting with implantation of the first ball-shaped osmotic expander into the soft tissue of the orbit, with a final volume of $2.0 \mathrm{ml}$ (diameter $15 \mathrm{~mm}$ ). In addition, a glass shell eye prosthesis with a central hole was brought into the conjunctival sac.

4. Whenever clinical impression dictated (i.e. reduced prominence of palpebral appara-

TABLE I

Concomitant Disorders in Conjunction with Clinical Anophthalmia

\begin{tabular}{cl}
\hline Case & Concomitant Disorder \\
\hline 3 & Internal hydrocephalus plus a cerebellar cyst \\
4 & Neurodermitis \\
5 & Agenesis of corpus callosum \\
6 & 4q Structural chromosomal anomaly in \\
& combination with brachycephaly \\
9 & Suprasellar subarachnoidal cyst plus \\
& neurodermitis \\
10 & Median cleft syndrome in combination with \\
& bilateral clefts of lip, alveolus and palate \\
& choroidea, and retina \\
11 & Ipsilateral cleft of lip, alveolus and palate \\
12 & Plagiocephaly with internal hydrocephalus \\
13 & Bilateral postminimus of the hands \\
16 & Contralateral sclerocornea (blind eye) \\
17 & Holoprosencephaly with partial fusion of \\
& anterior ventricles \\
18 & Bilateral oblique facial cleft \\
19 & Subcutaneous Tessier cleft no. 12 \\
20 & Oculo-auriculo-vertebral syndrome with \\
& (contralateral) cleft of lip, alveolus and \\
& palate, upper eye lid coloboma and deafness \\
& Contralateral microphthalmos \\
\hline
\end{tabular}


tus or "hollow-eye" appearance), the 2-ml, ballshaped expander was exchanged for a 3-ml (final volume) expander, in addition to the artificial eye in the conjunctival sac. The next steps were 4-ml and 5-ml expanders respectively.

5. The last step was exchanging the final expander for autogenous cartilage. (Currently, this has been done in one patient only).

\section{The Surgical Procedures Were Straightforward}

1. Under general anesthesia, the length of the palpebral fissure was first measured. Then, the not-yet-swollen hydrophilic, hemispheric osmotic expander was placed into the conjunctival sac and fixed like a button (with two holes) to the posterior conjunctival wall by means of a nonresorbable monofilament suture material (like nylon). Temporary blepharorrhaphy was done with a mattress suture of braided nonresorbable material in place for approximately 3 weeks or more.

2. Under general anesthesia, the nylon suture was cut, and the conjunctival expander was taken out (Fig. 5) and simply replaced by a conformer or artificial glass eye.

3. Under general anesthesia, after controlling and documenting the length of the palpebral fissure, the conformer, glass ball or glass eye was taken out from the conjunctival sac. After inspecting and flushing the conjunctiva, the posterior conjunctival wall was incised horizontally. Then, a pocket was created in the posterior soft-tissue compartment by blunt dissection. This was followed by implantation of the not-yet-swollen hydrophilic, spheric osmotic expander and a two-layered closure of the conjunctiva using resorbable material [like

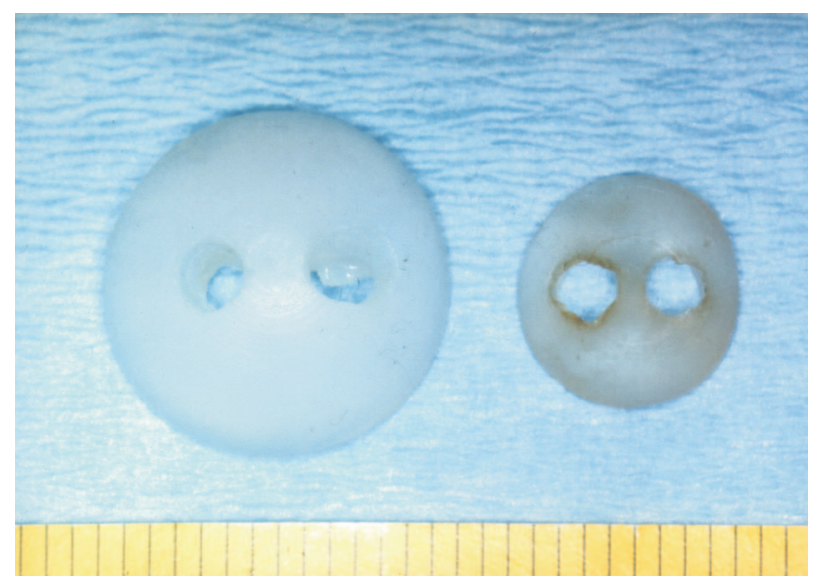

FIG. 5. Conjunctival expander swollen after water uptake (left) and in dry status (right) (having been taken out again). polyglactin, Vicryl (Ethicon, Hamburg, Germany]. Finally, a glass shell prosthesis was placed into the reconstructed conjunctival sac and retained there again by a temporary blepharorrhaphy. This helped to counteract the rising pressure produced by the increasing volume of the expander.

When exchanging the expander for a larger one, the fine capsule that was formed by connective tissue around the expander was to be incised in a circular fashion to accommodate the expanding implant of the next size.

The expander material was made of a copolymer on the basis of methylmethacrylate and Nvinylpyrrolidone. In the beginning, this hydrophilic substance has a hard consistency. By taking up water, it increases its volume and turns into a stiff gel (Fig. 5). The water absorption capacity could be regulated chemically to achieve a swelling factor between 3 and 30. The material applied was characterized by expansion factors of 7 to 13 (AcriTec, Glienicke bei Berlin, Germany).

In 17 of the 22 patients, magnetic resonance imaging scans (or computed tomography scans in the beginning of the series) were taken to make an exact diagnosis or for other diagnostic reasons and also to calculate the volumes of the orbits. The results were then compared with each other and a graph demonstrating the increase in volume as a consequence of therapy was created (Fig. 6). This graph also attempts to demonstrate the normal growth of the healthy orbits containing a globe.

While in the very beginning of our study, the routine diagnostic procedures included computed tomography (Tomoscan CR; Philips, Hamburg, Germany) it was soon changed to magnetic resonance imaging of the head. Follow-ups to control the growth of the orbits, therefore, most often included magnetic resonance imaging (Magnetom Expert; Siemens, Erlangen, Germany). Section slices were oriented transversally with a slice thickness varying from 1 to $2.8 \mathrm{~mm}$. Calculation of orbital volumes was performed according to the "summation of area" method using the Easy Vision Workstation (Philips, Hamburg, Germany). Definition of the bony orbit was by the bony walls with the anterior borders being the lower, lateral, and upper orbital margins as well as the lacrimal bone. The optic canal was not included. This was done three times in every patient and the arithmetic mean was accepted as the final value. 


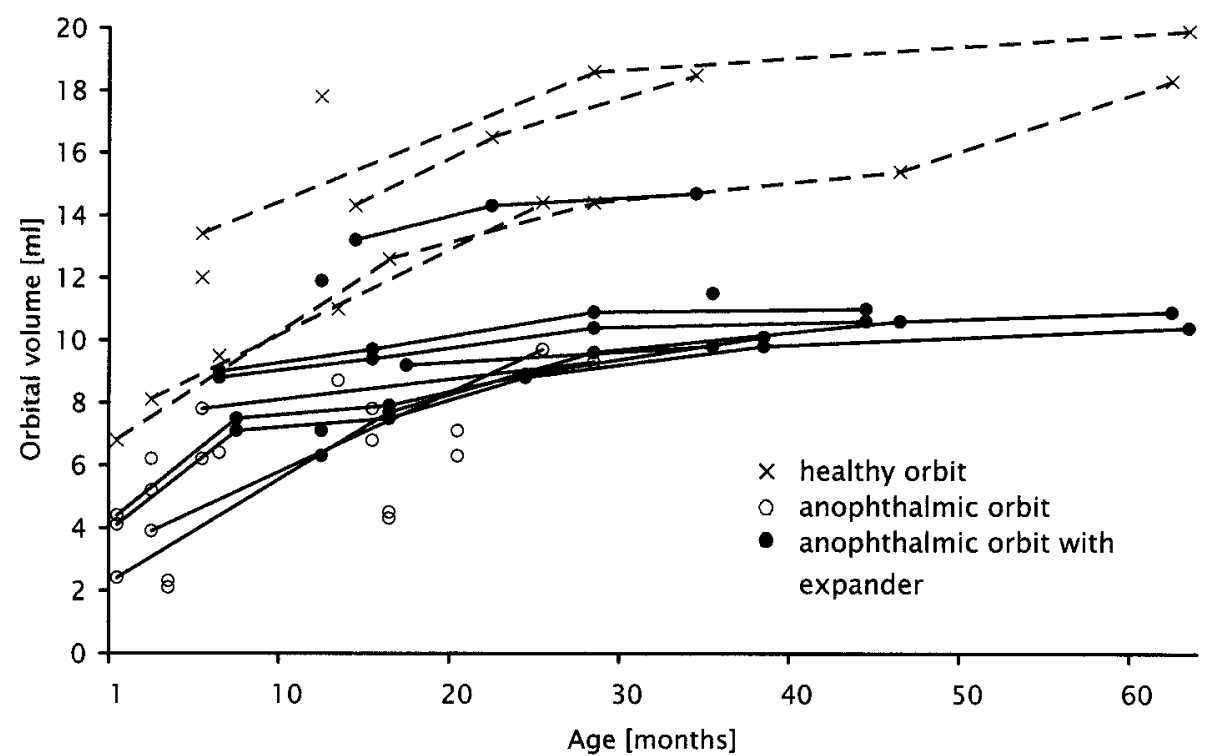

FIG. 6. Data of 17 patients (26 clinical anophthalmic orbits and 8 orbits with normal volume) to compare growth of healthy and anophthalmic orbits. ("Healthy orbits" refer to the normal ones evaluated on magnetic resonance imaging in unilateral cases. Affected orbits have been evaluated before (open circle) and after implantation of an expander (filled circle).

\section{RESULTS}

Altogether, 49 conjunctival socket expanders and 78 orbital expanders were implanted in the 22 patients who had a total of 32 anophthalmic orbits (Table II). The expander volumes still in place at the time this article was written measured between 0.9 and $5 \mathrm{ml}$. In five patients (seven orbits) there were only conjunctival but no orbital expanders implanted yet $(0.9 \mathrm{ml})$. In eight orbits, there were $2-\mathrm{ml}$ expanders, in seven orbits 3-ml expanders, in five orbits there were 4-ml expanders, and in four orbits there were 5-ml expanders implanted into the soft tissues behind the conjunctival sac. In one case, the last expander has already been exchanged for cartilage. (In two patients with bilateral anophthalmia, expanders of different sizes were in situ.)

Altogether, there were 14 failures with the conjunctival socket expanders and 21 failures with the orbital expanders. In two patients (both bilateral), conformers were made of a different material. In another patient, dermis fat grafts had been implanted at another institution before being referred to Rostock.

The 35 total failures experienced out of 127 total expanders mostly were due to either poor surgery or the wrong implant shape or size chosen. The mistakes made during surgery were either not incising the peri-implant capsule when introducing an orbital expander of the next size, neglecting closure of the conjunctiva in two layers, or not respecting the perioperative antibiotic regimen. It turned out to be necessary not only to give systemic antibiotics intraoperatively but also to apply an antibiotic ointment (or drops) into the conjunctival sac for several days postoperatively (starting directly at the end of the operation).

Regarding size and shape, one conjunctival expander was too small and fell out of the socket; another eight conjunctival expanders were scraped out of the socket by the little patients with their fingernails when being at home (they were less than 24 months old); two orbital expanders were too large; four expanders were the wrong shape (not spheric or not consisting of one piece only). All complications could be corrected with another procedure. There has not yet been an irreparable failure.

When calculating the growth of the orbits, a comparison of the growth of the anophthalmic with that of the unaffected orbits was attempted. Seventeen of the patients were scanned due to other reasons: 10 were scanned once, two twice, two 3 times, one 4 times, and two 5 times during the various stages of treatment (Fig. 6). These scans were used for calculating the volumes of the orbit. It became apparent that up to 6 months of age, the anophthalmic orbits without an expander had a 
TABLE II

Cases Treated with Osmotic Expanders (According to Age)

\begin{tabular}{|c|c|c|c|c|c|c|}
\hline Case & $\begin{array}{c}\text { Orbit } \\
\text { involved }\end{array}$ & $\begin{array}{c}\text { No. of } \\
\text { Conjunctival } \\
\text { Expanders }\end{array}$ & $\begin{array}{l}\text { No. of } \\
\text { Failures with } \\
\text { Conjunctival } \\
\text { Expanders }\end{array}$ & $\begin{array}{l}\text { No. of Orbital } \\
\text { Expanders }\end{array}$ & $\begin{array}{l}\text { No. of Failures } \\
\text { with Orbital } \\
\text { Expanders }\end{array}$ & $\begin{array}{l}\text { Last Volume of } \\
\text { Expander in Situ } \\
\text { (for the time being) }\end{array}$ \\
\hline 1 & Right & 1 & 0 & $4^{*}$ & 0 & Cartilage \\
\hline 2 & Right & 2 & 0 & 3 & 0 & $4 \mathrm{ml}$ \\
\hline 3 & Right & 2 & 1 & 4 & 1 & $4 \mathrm{ml}$ \\
\hline 3 & Left & 2 & 1 & 4 & 1 & $3 \mathrm{ml}$ \\
\hline 4 & Right & 3 & 2 & 6 & 3 & $4 \mathrm{ml}$ \\
\hline 5 & Right & 1 & 0 & 1 & 0 & $2 \mathrm{ml}$ \\
\hline 5 & Left & 2 & 0 & 2 & 2 & $0.9 \mathrm{ml}$ \\
\hline 6 & Right & 2 & 1 & 3 & 2 & $2 \mathrm{ml}$ \\
\hline 6 & Left & 2 & 1 & 4 & 3 & $2 \mathrm{ml}$ \\
\hline 7 & Right & 2 & 1 & 0 & 0 & $0.9 \mathrm{ml}$ \\
\hline 7 & Left & 2 & 1 & 0 & 0 & $0.9 \mathrm{ml}$ \\
\hline 8 & Right & 1 & 0 & 7 & 3 & $5 \mathrm{ml}$ \\
\hline 8 & Left & 1 & 0 & 4 & 0 & $5 \mathrm{ml}$ \\
\hline 9 & Right & 1 & 0 & 5 & 1 & $5 \mathrm{ml}$ \\
\hline 9 & Left & 1 & 0 & 4 & 0 & $5 \mathrm{ml}$ \\
\hline 10 & Left & 1 & 0 & 0 & 0 & $0.9 \mathrm{ml}$ \\
\hline 11 & Right & 2 & 0 & 4 & 1 & $4 \mathrm{ml}$ \\
\hline 12 & Left & 1 & 0 & 1 & 0 & $2 \mathrm{ml}$ \\
\hline 13 & Right & $2^{\dagger}$ & 1 & 0 & 0 & $0.9 \mathrm{ml}$ \\
\hline 13 & Left & 2 & 1 & 0 & 0 & $0.9 \mathrm{ml}$ \\
\hline 14 & Right & 1 & 0 & 2 & 0 & $3 \mathrm{ml}$ \\
\hline 14 & Left & 1 & 0 & 4 & 2 & $3 \mathrm{ml}$ \\
\hline 15 & Right & $2^{\dagger}$ & 1 & 4 & 1 & $4 \mathrm{ml}$ \\
\hline 16 & Right & 1 & 0 & 2 & 1 & $2 \mathrm{ml}$ \\
\hline 17 & Right & 1 & 0 & 2 & 0 & $3 \mathrm{ml}$ \\
\hline 17 & Left & 2 & 1 & 2 & 0 & $3 \mathrm{ml}$ \\
\hline 18 & Left & 1 & 0 & 1 & 0 & $2 \mathrm{ml}$ \\
\hline 19 & Right & 1 & 0 & 2 & 0 & $3 \mathrm{ml}$ \\
\hline 20 & Right & 1 & 0 & 1 & 0 & $3 \mathrm{ml}$ \\
\hline 21 & Right & 2 & 1 & 1 & 0 & $2 \mathrm{ml}$ \\
\hline 21 & Left & 1 & 0 & 1 & 0 & $2 \mathrm{ml}$ \\
\hline 22 & Right & 2 & 1 & 0 & 0 & $0.9 \mathrm{ml}$ \\
\hline Total & 32 & 49 & 14 & 78 & 21 & \\
\hline
\end{tabular}

* First case in series.

$\dagger$ In cases 13 and 15, a lentil-shaped then a ball-shaped conjunctival expander was implanted into the conjunctival sac.

volume of only 46 percent (mean) of those orbits with a globe (4.3 instead of $9.4 \mathrm{ml}$ ).

On average, the length of the palpebral fissures was only $12 \mathrm{~mm}$ rather than $19 \mathrm{~mm}$ (60 percent). After implantation of an osmotic expander, the length of the palpebral fissures grew up to an average of $16 \mathrm{~mm}$ (70 percent of the length of the healthy fissure measuring 23 $\mathrm{mm}$ ) at age 2 and to $19 \mathrm{~mm}$ (mean) at 4 years of age and older. This is 73 percent of the normal (i.e. $7 \mathrm{~mm}$ shorter than the length of the healthy palpebral fissures) (mean of 26 $\mathrm{mm}$ ). At the same time, the relative size of the anophthalmic orbits grew and during the first year (13 to 18 months of age) as well as 3 years of age and older (25 to 62 months of age), the sizes amounted to 70 percent $(10.1 \mathrm{ml}$ instead of $14.4 \mathrm{ml}$ ) and 64 percent of the normal, i.e., nonanophthalmic orbits on average (10.3 instead of $16.0 \mathrm{ml}$ ) respectively.

\section{DISCUSSION}

Clinical anophthalmia is rare, with between 1 in 50,000 newborns ${ }^{13}$ and 11 in 50,000 newborns having the condition. ${ }^{14}$ Thus, the 22 patients followed up for several years were thought to be a considerable number and worthy of a report.

There are several articles published on successful incorporation of eye prostheses in anophthalmic patients. They are often only on acquired anophthalmias that were described as not having or developing a deficit in volume. ${ }^{15,16,17}$ It was, therefore, of interest to study the growth of the bony orbit in patients with congenital clinical anophthalmia who were treated according to the method just described. ${ }^{11}$ It is known that the fetal orbital diameter enlarges from $5.2 \mathrm{~mm}$ at 14 weeks gestational age to $15.8 \mathrm{~mm}$ at 34 to 36 weeks 
gestational age. ${ }^{18}$ In the seventh month of intrauterine life, the eyes have grown so much that only half of the eyeball fits into the bony orbit. At the time of birth the eyeballs are said to have a volume of $2.5 \mathrm{ml} .{ }^{19,20}$ Therefore, it was considered appropriate to start with an expander volume of $2 \mathrm{ml}$ when treating these patients.

The eye and the orbit grow the fastest during the first year of life. Seventy percent of the increase of the globe's volume occurs by 4 years of age and 90 percent by age $7 .{ }^{21}$ While growth of the eye ends at age $14,{ }^{22}$ the growth of the orbit ends at age 11 in females and at age 15 in males. ${ }^{23}$ This is why enlarging the orbit in the first years of life should be attempted. It is known that the developing eye, being part of the "functional matrix," has a marked effect on orbital growth.

Various techniques have been described to enlarge not only the socket but also the bony orbit. Probably the simplest method to do this is implantation and serial exchange for ever bigger solid prostheses into the socket, i.e., aiming at enlarging the conjunctival sac. ${ }^{24-26}$ Another idea was to implant dermis fat grafts that would grow and, thus, exert some pressure onto the bony walls of the orbit. ${ }^{27}$ It was a major step forward when Tessier ${ }^{7}$ et al. started to enlarge the orbits by osteotomy and expansion. ${ }^{28-30}$ The next idea was expansion by inflated silicone tissue expanders. ${ }^{9,10,24}$ There were also ideas of combining an osteotomy with a tissue expander ${ }^{21,31}$ or applying pulsation to the tissue expanders implanted into the orbit. ${ }^{32}$ However, there were several shortcomings described in the literature leading to disappointing side effects like decrease of interorbital distance and a high percentage of extrusions of these expanders. ${ }^{21,24}$ In addition, not every patient having been treated by the techniques described was able to wear an artificial eye. In contrast, all the patients treated by means of the expanders described in this article were able to wear an artificial eye without any problem.

Another good idea was hydrophilic, and, thereby, self-inflating, expanders made of various substances. ${ }^{24,33}$ It was Wiese's original idea to use a copolymer of methylmethacrylate and $\mathrm{N}$-vinylpyrrolidon for this purpose. While polyhydroxyethylemethacrylate swells only to a moderate degree (x 1.7) the methylmethacrylate-N-vinylpyrrolidon swells much more when placed into a physiological saline solution. This can even be enhanced to a factor of 20 or more when changing the composition of the material. ${ }^{34}$ The expanders (AcriTec; GmbH, Glienecke/Berlin, Germany) used in this series of patients were $0.27 \pm 0.03 \mathrm{ml}$ (for the smaller ones) or $0.38 \pm 0.03 \mathrm{ml}$ (for the bigger ones) before implantation and grew, according to the various swelling factors, up to a final volume of $2,3,4$, or $5 \mathrm{ml}$ ( $\pm 0.03 \mathrm{ml}$ ) respectively. The final expanders to be implanted have a volume of $5 \mathrm{ml}$ as the physiological volume of the globe has been described to be approx. 7.0 $\mathrm{ml}$ (i.e., 32 percent of the orbital volume). ${ }^{20}$ When adding the volume of the eye prosthesis to the $5 \mathrm{ml}$ of the expander the result will be almost $7 \mathrm{ml}$.

In the patients under our care, the eyelid apparatus was also stimulated to grow from 60 percent of normal palpebral fissure length at 6 months of age to 73 percent at 4 years of age or more (Fig. 7). All patients could incorporate an artificial eye easily, but the most interesting question was whether it was possible to induce growth of the bony orbit. Up to now, this had been achieved successfully in animals by using tissue expanders. ${ }^{35}$ But there are no experiments in congenitally anophthalmic animal models. Most animals do not have a bony continuity of the orbit like humans have. There also has been only little evidence for growth of the bony orbit in congenital anophthalmia in human patients, regardless of what kind of implants were used. .4-26 $^{-}$

Several problems were encountered when evaluating bony orbits to measure growth. There was a difficulty to define the actual "borders" of the bony orbit. This, therefore, was done three times for every patient and for every series of magnetic resonance imaging by one person only on one day only. There was no "yardstick" for this measurement, as neither the volume of the eyeball nor of the expander was known exactly. Comparison with other articles was even more difficult since those researchers have not defined the "borders" exactly the same way as we did and one has to consider that a 60 percent size in one dimension does not equal a 60 percent size when considering all three dimensions of the orbit (rather 20 to 25 percent only). The missing data on growth of untreated anophthalmic orbits is another shortcoming. There are very few reports on the orbital volume of such patients. Kennedy $^{36}$ described the volumes found in such a patient (according to Tucker ${ }^{24}$ ) and 

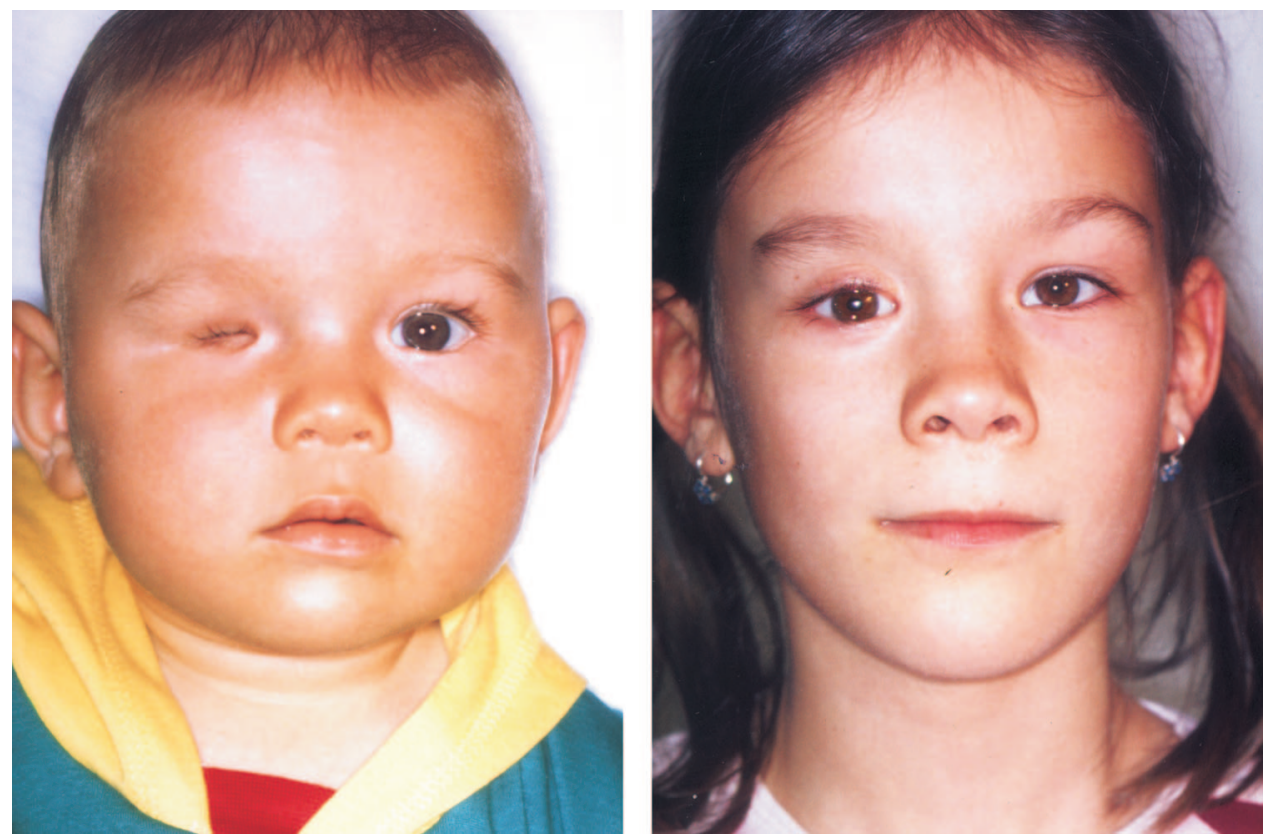

Fig. 7. (Left) A 24-month-old girl with congenital clinical anophthalmia of the right eye. (Right) Same girl at age 7, wearing an osmotic orbital expander (of only $3 \mathrm{ml}$ ) and an artificial eye (first patient of this series; case no. 1. (Schittkowski, M. P., Gundlach, K. K., and Guthoff, R. F. Congenital clinical anophthalmia and blind microphthalmia. Der Ophthalmologe 100: 507, 2003.)

found 60 percent of the volume in the anophthalmic orbit when compared with the healthy orbit. This figure was also reported by Hare. ${ }^{37}$ Santler et al. ${ }^{31}$ reported on a 5 -year-old boy who had only a $5.2 \mathrm{ml}$ anophthalmic orbit compared with his $20.3 \mathrm{ml}$ healthy orbit. Gossman et al..$^{25}$ described an average deficit of between 8 and 25 percent (mean 15 percent) in five patients with microphthalmia at the age of 10 months to 6 years (mean 2.3 years) when calculating only the one-dimensional mid-orbital width before therapy. Taking those data into consideration, the results published in this article seem to be convincing, though maybe not yet exciting. However, it was found that growth of both the palpebral fissure length and the volume of the bony orbit was stimulated. It is believed that the data presented are encouraging and the cosmetic appearance of the patients is very pleasing.

\section{Conclusions}

Using the self-inflating substance of methylmethacrylate-N-vinylpyrrolidon is a promising way to induce further growth of an anophthalmic orbit. The technique described is safe, simple, and almost harmless. The palpebral fissure is lengthened, the conjunctival sac is expanded, the bony orbit is stimulated to grow, and the aesthetic result is pleasing and promises to be long-lasting.

Karsten K. H. Gundlach, M.D., D.D.S., M.S.D.

Department of Craniomaxillofacial Surgery

University of Rostock

Strempelstrasse 13

D-18057 Rostock

Germany

\section{REFERENCES}

1. Opitz, J. M. Editorial comment: The developmental field concept. Am. J. Med. Genet. 21: 1, 1985.

2. Gundlach, K. K. H., and Pfeifer, G. Classification of facial malformations. Int. J. Oral Surg. 10: (Suppl.): 267, 1981.

3. Gundlach, K. K. H. Is Pfeifer's frontonasal region identical with Opitz's midline developmental region? In: R. Vogel, J. Fanghänel, and T. Koppe (Eds.), Aspects of Teratology, Vol. 2. Marburg:Tectum, 2001. Pp. 26-30

4. Gorlin, R. J., Pindborg, J.J., and Cohen, M. M. Syndromes of the Head and Neck, 2nd Ed. New York: McGraw-Hill, 1976.

5. Sarnat, B. G. The orbit and eye: Experiments on volume in young and adult rabbits. Acta Ophthalmol. 147: 1, 1981.

6. Sarnat, B. G., and Shanedling, P. D. Orbital volume following evisceration, enucleation and exenteration in rabbits. Am. J. Ophthalmol. 70: 787, 1970.

7. Tessier, P. Microphthalmias and congenital anophthalmias. In: P. Tessier, J. Rougier, F. Hervouet, et al. (Eds.), Plastic Surgery of the Orbit and Eyelids. New York: Masson, 1981. Pp. 187-188.

8. Mustardé, J. C. The eye socket, anophthalmos.. In: J. C. Mustardé, Repair and Reconstruction in the Orbital Region, 
2nd Ed. Edinburgh: Churchill Livingstone, 1980. Pp. 231.

9. Wolfe, S. A. Microphthalmos. In: S. A. Wolfe and S. Berkowitz (Eds.) Plastic Surgery of the Facial Skeleton, Boston: Little, Brown \& Co., 1989. P. 670.

10. Krastinova, D., Kelly, M. B. H., and Mihaylova, M. Surgical management of the anophthalmic orbit, Part I: Congenital. Plast. Reconstr. Surg.108: 817, 2001.

11. Wiese, K. G., Vogel, M., Guthoff, R., and Gundlach, K. K. H. Treatment of congenital anophthalmus with self-inflating polymer expanders: A new method. $J$. Craniomaxillofac. Surg.27: 72, 1999.

12. Gundlach, K. K. H., and Guthoff, R. Treatment of anophthalmia using osmotic hydrogel expanders. In: J. Lilja (Ed.), Transactions 9th International Congress on Cleft Palate and Related Craniofacial Anomalies. Gothenborg: Erlanders Novum, 2001. Pp. 459-464.

13. Bermejo E., and Martínez-Frías, M.-L. Congenital eye malformations: Clinical-epidermiological analysis of 1,124,654 consecutive births in Spain. Am. J. Med. Genet. 75: 497, 1998.

14. O'Keefe, M., Webb, M., Pahby, R. C., and Wagman, R. Clinical anophthalmos. Br. J. Ophthalmol. 11: 635, 1987.

15. Yago, K., and Furuta, M. Orbital growth after unilateral enucleation in infancy without an orbital implant. Jpn. J. Ophthalmol. 45: 648, 2001.

16. Fountain, T. R., Goldberger, S., and Murphree, A. L. Orbital development after enucleation in early childhood. Ophth. Plast. Reconstr. Surg. 15: 32, 1999.

17. Hintschich, C., Zonnefeld, F., Baldeschi, L., Bunce, C., and Koornneef, L. Bony orbital development after early enucleation in humans. Br.J. Ophthalmol. 85: 205, 2001.

18. Goldstein, I., Tamir, A., Zimmer, E. Z., and ItskovitzEldor, J. Growth of the fetal orbit and lens in normal pregnancies. Ultrasound Obstet. Gynecol. 12: 175, 1998.

19. Schultz, A. H. The size of the orbit and of the eye in primates. Am. J. Phys. Anthrop. 26: 389, 1940.

20. Vistnes, L. M. Surgical Reconstruction in the Anophthalmic Orbit. Birmingham, Alabama: Aesculapius Publication Company, 1987.

21. Dunaway, D. J., and David, D. J. Intraorbital tissue expansion in the management of congenital anophthalmos. Br. J. Plast. Surg. 49: 529, 1996.

22. Sinclair, D., and Dangerfield, P. Nervous system. In D. Sinclair and P. Dangerfield (Eds.), Human Growth after Birth, Oxford: Oxford University Press, 1998. P. 87.
23. Furuta, M. Measurement of orbital volume by computed tomography: Especially on the growth of orbit. J. Jpn. Ophthalmol. 104: 724, 2000.

24. Tucker, S., Sapp, N., and Collin, R. Orbital expansion of the congenitally anophthalmic socket. Br. J. Ophthalmol. 79: 667, 1995.

25. Gossman, M. D., Mohay, J., and Roberts, D. M. Expansion of the human microphthalmic orbit. Ophthalmology 106: 2005, 1999.

26. Sterker, I., Klapper, H.-U., Wiedemann, P., and Reiber, T. Klinischer Anophthalmus. Klin. Monatsbl. Augenheilkd. 216: 197, 2000.

27. Handler, L. F., Heher, K. L., and Katowitz, J. A. Congenital and acquired anophthalmia. Curr. Opin. Ophthalmol. 5: 84, 1994

28. Marchac, D., Cophignon, J., Achard, E., and Dufourmentel, C. Orbital expansion for anophthalmia and micro-orbitism. Plast. Reconstr. Surg. 59: 486, 1977.

29. Lee, Y. H., Kim, H. C., Lee, J. S., and Park, W. J. Surgical reconstruction of the contracted orbit. Plast. Reconstr. Surg 103: 1129, 1999.

30. Wolfe, S. A. Surgical reconstruction of the contracted orbit (Discussion). Plast. Reconstr. Surg. 103: 1137, 1999.

31. Santler, G., Kärcher, H., and Mossböck, R. Simultaneous orbital expansion and intraoral distraction osteogenesis of upper and lower jaws in a patient with hemifacial microsomia. J. Craniomaxillofac. Surg. 31: 228, 2003

32. Wagner, A., Schneider, C., Lagogiannis, G., and Hollman, K. Pulsatile expansion therapy for orbital enlargement. Int. J. Oral Maxillofac. Surg. 29: 91, 2000.

33. Steinkogler, F. J., and Polzhofer, K. HEMA-socket-expander in der primär konservativen Behandlung des kongenitalen Anophthalmus. Klin. Monatsbl. Augenheilkd. 191: 240, 1987.

34. Wiese, K. G. Gewebedehnung mit osmotisch-aktiven Hydrogelsystemen. Berlin: Quintessenz, 1998.

35. Eppley, B. L., Holley, S., and Sadove, A. M. Experimental effects of intraorbital tissue expansion in orbitomaxillary growth in anophthalmos. Ann. Plast. Surg. 31: 19, 1993.

36. Kennedy, R. E. Growth retardation and volume determinations of the anophthalmic orbit. Trans. Am. Ophthalmol. Soc. (U.K.) 70: 277, 1972.

37. Hare, R. Congenital bilateral anophthalmos. Arch. Ophthalmol. 30: 320, 1943. 